\title{
AVALIAÇÃO DE DESEMPENHO DOCENTE E SUPERVISÃO PEDAGÓGICA: VENENO E ANTÍDOTO NO MESMO PACOTE?
}

\author{
Sandra Alves Soares*
}

\begin{abstract}
Resumo: Sendo a avaliação de professores um processo cuja finalidade consiste em determinar o desempenho dos docentes no contexto de um vasto conjunto de circunstâncias, a necessidade de uma ação supervisiva contínua e reflexiva, de forma a assegurar a melhoria individual, institucional e da qualidade do sistema educativo afigura-se como fulcral. Contudo, são cada vez mais questionáveis as finalidades da avaliação docente quando associadas à melhoria dos resultados dos alunos e da qualidade das suas aprendizagens por comparação com as que remetem para o desenvolvimento pessoal e profissional. Objetivou-se, com exte texto, tecer uma breve análise reflexiva sobre o verdadeiro papel que a Avaliação de Desempenho Docente $(A D D)$ exerce no campo da Supervisão Pedagógica (SP), através de uma breve revisão da literatura onde se enquadraram estes e outros conceitos naquele que é o centro nevrálgico desta reflexão crítica: analisar o impacto e operacionalização que a ADD regista no campo da SP, ou seja, averiguar qual é, afinal, o "peso" e a incidência que esta avaliação acaba por ter na qualidade da SP, tendo em conta os princípios e pressupostos que a regem. Complementa-se este intento com a apresentação de um caso real de observação de aulas.
\end{abstract}

Palavras-chave: Supervisão pedagógica, Avaliação de Desempenho Docente, Observação de aulas; Desenvolvimento profissional; Prestação de contas.

\begin{abstract}
The teacher evaluation is a process whose purpose is to determine the performance of teachers within a broad range of circumstances so, the need for a continuous and reflexive action on supervision, to ensure the improvement on the individual and institutional quality of the education system, is crucial. However, it is
\end{abstract}

\footnotetext{
* Professora do ensino básico e secundário. Licenciada em Línguas e Literaturas Modernas, variante de Estudos Portugueses e Ingleses. Mestre em Ciências da Educação - Administração e Organização Escolar e Formação Especializada em Orientação Educativa/Direção de Turma e Supervisão Pedagógica e Avaliação do Desempenho Docente.
} 
increasingly questionable the purposes of teacher evaluation when associated with the improvement on student results and the quality of their learning compared to those that refer to personal and professional development. Our aim is to undertake a brief reflexive analysis on the true role that the Teacher Performance Assessment $(A D D)$ has on the field of Supervision $(S P)$, through a brief review of the literature where these and other concepts frame the center of this critical reflection: analyzing the impact that the ADD has in the field of SP, i.e., find out what is, after all, the "weight" and the incidence that this assessment turns out to have on the quality of SP, taking into account its principles and assumptions. This intent is complemented by presenting a real case of classroom observation.

Keywords: Supervision teaching, teacher performance assessment, classroom observation, professional development; accountability.

\section{INTRODUÇÃO}

São inúmeras as reformas educativas que os sucessivos governos têm procurado implementar, objetivando a elevação dos padrões do ensino e a melhoria da qualidade das aprendizagens dos alunos. O produto final a alcançar encerra em si a constatação de que a prestação de contas é, indubitavelmente, de fulcral relevância. Por essa razão e de acordo com Stronge (2010: 24), a Avaliação do Desempenho Docente enquanto "empreendimento cada vez mais significativo e útil" exige respostas às muitas questões que se prendem diretamente com os justificativos, os objetivos / propósitos e os resultados desta prática. Reveste-se, claramente, de uma importância significativa que, no âmbito de uma esfera complexa, sugere múltiplas dimensões, sentidos e implicações. Assim, ao invés de funcionar como uma "ferramenta essencial para apoiar e melhorar a qualidade do ensino" (idem: 29), a avaliação de professores tem, muitas vezes, sido desvalorizada na medida em que, frequentemente, deriva de um procedimento puramente burocrático, sendo levada a cabo como uma "mera formalidade" (idem). Também Vieira e Moreira (2011: 23) se pronunciam a este respeito para realçar que ao colocarmos a supervisão e a avaliação "ao serviço da dignidade docente", estaremos também a "lutar contra a burocratização crescente e asfixiante do trabalho docente".

Partindo do pressuposto que a avaliação docente implica, por si só, um abrangente leque de diferentes circunstâncias, o caráter contínuo e reflexivo da ação supervisiva aumenta significativamente pois será este o garante da melhoria dos indivíduos, da organização escolar mas também da qualidade do sistema educativo. Assim, uma avaliação de desempenho de qualidade constitui-se, inequivocamente, como um dispositivo reprodutor da promoção da aprendizagem ao longo da vida e, por conseguinte, da eficácia pedagógica das práticas docentes. 
No âmbito desta ação supervisiva surge o conceito de supervisão pedagógica que, não sendo propriamente recente, acaba por assumir, com a implementação dos recentes modelos de ADD, um estatuto de significativa relevância. Efetivamente, no atual contexto de mudança do exercício da profissão docente, a supervisão pedagógica associa-se à observação de aulas de todos os professores em geral e não apenas daqueles que se encontram em formação inicial como até há uns anos atrás era entendida e considerada. Reis (2011: 7) defende que a observação de aulas e de outros contextos escolares pode ocorrer, efetivamente, em processos supervisivos distintos e/ou com objetivos igualmente distintos como, por exemplo, no período probatório de um docente (para promover a sua integração na comunidade educativa e nas funções a desempenhar); na fase de estágio de iniciação à prática profissional (com o apoio de um mentor ou supervisor); no âmbito de processos informais de apoio e desenvolvimento profissional (grupos de docentes envolvidos na análise e discussão recíprocas de aulas); decorrente de processos formais da ADD (capazes de reconhecer o mérito, constituir um desafio e servir de apoio para identificar e superar fragilidades).

Ora, esta "nova" realidade transporta uma também "estreante" situação que está longe de ser vista como pacífica e/ou isenta de controvérsia, na medida em que, como sabemos, a observação de aulas não foi, no nosso país e até um passado bastante recente, uma prática comum e, muito menos, instituída entre os professores. Não obstante, e ao longo das últimas duas décadas, tem-se verificado uma maior tendência (sobretudo a nível internacional) para considerar a observação de aulas como um "processo de interação profissional, de carácter essencialmente formativo, centrado no desenvolvimento individual e colectivo dos professores e na melhoria da qualidade do ensino e das aprendizagens" (Reis, 2011: 11).

No nosso país e na nossa opinião, a observação de aulas tem sido, sobremaneira, apreendida e reconhecida fundamentalmente enquanto processo supervisivo de situações formais (ADD). Por esta razão e na opinião autor supracitado, tem-se tornado num assunto bastante sensível de onde decorrem, em grande parte, três grandes preocupações: a primeira implica a indagação acerca de se poder certificar (ou não) que as observações realizadas permitem (quantitativa e qualitativamente) "a construção de uma imagem clara e completa das competências profissionais do professor observado"; a segunda compreende a inquietação quanto ao facto de se poder aferir até que ponto as práticas observadas constituem exemplos das práticas diárias; a terceira resulta da apreensão quanto à existência, por parte dos observadores, de competências profissionais para o desempenho da tarefa avaliativa.

$\mathrm{Na}$ verdade, e tal como retratam Vieira e Moreira (2011: 11), a necessidade de supervisão não decorre necessariamente da avaliação de desempenho mas constitui um "imperativo da acção profissional consciente e deliberada". Com efeito, a "pedagogia sem supervisão será menos 
pedagógica" o que pressupõe que cada professor deve regular criticamente a sua prática, ou seja, promover o que estas autoras designam de "autosupervisão" enquanto estratégia básica de autoavaliação e de desenvolvimento profissional, independentemente de quaisquer outras formas de supervisão, nomeadamente da que se reduz à supervisão formal que tem sido, na nossa opinião, sobrevalorizada.

\section{SUPERVISÃO PEDAGÓGICA VS AVALIAÇÃO DE DESEMPENHO DOCENTE?}

Numa primeira instância e para melhor introduzirmos a nossa perspetiva na abordagem a este assunto, parece-nos oportuno clarificar ambos os conceitos. Na verdade, o conceito de supervisão pedagógica ultrapassa, cada vez mais, as "fronteiras" da formação de profissionais destinados à docência e em formação inicial a que nos habituámos a relacionar. O conceito surge ainda como tema de uma literatura cada vez mais consistente e lata, realizada por diversos investigadores e autores que abordam o tema procurando, por um lado, contribuir para a (re)qualificação dos profissionais em exercício que trabalham em educação, e, por outro, unir este objetivo ao da melhoria da qualidade da Escola. Paralelamente, e tal como anteriormente referido, foi incluída no contexto da ADD o que concomitantemente aumentou e engrandeceu o seu grau de importância.

Vieira e Moreira (2011: 11) esclarecem o conceito de supervisão pedagógica argumentando que o seu foco de atenção se centra na sala de aula, "podendo reportar-se a situações de auto-supervisão e supervisão acompanhada em qualquer cenário de desenvolvimento profissional, incluindo o da avaliação do desempenho". Alarcão e Roldão (2010: 54) remetem a noção de supervisão para a "criação e sustentação de ambientes promotores da construção e do desenvolvimento profissional, num percurso sustentado, de progressivo desenvolvimento da autonomia profissional". Por esta razão, a própria natureza do trabalho supervisivo que questiona, que interpreta, que teoriza e que reflete se assente numa base de acompanhamento e discussão permanente do processo e da ação e seus resultados, será um "alicerce para a construção do conhecimento profissional" (idem).

Independentemente das diferentes teorias e estudos sobre a supervisão pedagógica, bem como dos vários modelos de práticas reconhecidas como é o caso do behaviorista, do clínico, do psicopedagógico, do modelo de diagnóstico, entre outros, o que parece comummente consensual é a relevância do processo supervisivo na construção e desenvolvimento do professor enquanto indivíduo aprendente, colaborativo e reflexivo. Trata-se da tal preocupação que, na opinião de Vieira e Moreira (2011: 14), se prende com "o desenvolvimento da reflexividade profissional dos professores para a melhoria da qualidade das aprendizagens dos alunos". Assim, parece-nos justo afirmar que a supervisão, se encarada numa perspetiva construtivista que não se reduz à formação inicial e que se concretiza em união com a 
aprendizagem e melhoria de práticas ao longo da vida, pode, indubitavelmente, constituir um valioso contributo para o crescimento pessoal e profissional e para a melhoria da qualidade na educação, tornandose de extrema relevância quanto a uma maior capacidade para se adquirir/reciclar conhecimentos. (Lamy, 2009).

Concomitantemente, afigura-se como fulcral a reorientação das práticas de supervisão, nomeadamente no que concerne aos papéis dos atores que nela participam através da consecução de uma série de princípios gerais que pressupõem a definição das finalidades, conteúdos e tarefas da supervisão (articulando a prática reflexiva e a pedagogia para a autonomia); a indagação de teorias, práticas e contextos capazes de conduzir o professor a uma maior capacidade crítica e criativa do seu saber profissional; a concretização e avaliação de planos de intervenção; a criação de espaços de decisão do professor e de criação de condições e critérios como a reflexividade, a negociação e a regulação; a promoção de uma comunicação dialógica (através do cruzamento de experiências, interesses, expetativas...); a avaliação participada. (Vieira \& Moreira, 2011: 15).

No atinente à avaliação dos professores e atentando, na opinião de Formosinho (2010: 106) às suas quatro principais finalidades centradas na prestação de contas; na gestão das carreiras profissionais; no desenvolvimento pessoal e profissional do docente e na melhoria global do sistema de ensino, verificamos que as mesmas se direcionam para diferentes destinatários e objetos, intenções e usos sociais. Tal pressupõe, igualmente, distintos indicadores e instrumentos que, em conjunto com os objetivos, as funções e os contextos de avaliação, acabam por se converter em "utensílios" capazes de produzir um resultado a partir da observação direta e pela análise das evidências apresentadas.

O novo regime de avaliação estabelece uma série de associações, nomeadamente entre o perfil geral de competências para o desempenho da docência e o desenvolvimento profissional, os objetivos individuais do professor e os documentos instrumentais da autonomia da escola, priorizando o desenvolvimento pessoal e profissional do professor e a ação docente enquanto espaço privilegiado de uma formação crítica e reflexiva. Este aspeto conduz-nos a um novo enquadramento da supervisão que se afirma como o expoente máximo de uma avaliação formativa, de caráter reflexivo e colaborativo.

O paradigma que parece existir prende-se com o conflito que se gera entre os dois conceitos. Com efeito, no contexto que vivemos da ADD, ambos tendem a instituir-se, sobretudo, como mecanismos de conformidade e de reprodução, sendo subvalorizada a sua aplicação enquanto estratégias de transgressão e transformação. (Vieira e Moreira, 2011: 8). Na realidade, tal verifica-se porque se pressupõe que legitimem a qualidade da avaliação que é levada a cabo através de um rigoroso processo gerado a partir da definição de objetivos e padrões supostamente universais. O dilema surge justamente no 
conflito que daí deriva entre os propósitos formativos de desenvolvimento profissional e os propósitos sumativos de seleção e progressão na carreira. Por outras palavras, no quadro de um sistema de avaliação que se foca, como já anteriormente referido, na prestação de contas, como será possível potenciar o papel transformador e emancipatório dos dois conceitos quando ambos assumem, igualmente, funções de controlo e seriação? Neste contexto, importa, ainda, equacionarmos se a ADD poderá estar ao serviço das finalidades de melhoria dos resultados escolares dos alunos e da qualidade das suas aprendizagens e, simultaneamente, potenciar o desenvolvimento pessoal e profissional enquadrado num sistema de reconhecimento do mérito e da excelência, da dignificação da carreira docente e da promoção da autoestima e motivação dos professores. Mais ainda: atendendo a este enquadramento, questionamo-nos se não se encontrarão, ainda que inadvertidamente, um veneno e um antídoto no mesmo pacote, no mesmo processo. Há que recordar que subsistem, na nossa sociedade, muitos "venenos" necessários, que acabam por ser o melhor remédio para "males" piores. Encaremos o "veneno" aqui descrito desse modo.

Já no que concerne às finalidades de ambos os conceitos descritos, estas são, do mesmo modo, distintas pois a supervisão visa promover o desenvolvimento profissional do professor, enquanto a avaliação procura formular juízos relativos à sua competência, como anteriormente referimos. Como destaca Moreira (2009: 252) o primeiro visa "constituir-se enquanto processo de crescimento e desenvolvimento profissional, centrado na melhoria da acção e do desempenho profissional", enquanto o segundo procura "certificar a competência do professor para o exercício da actividade profissional, com impacto na progressão na carreira". Diferentes são, do mesmo modo, os princípios, o âmbito, o posicionamento perante a competência profissional, a forma como o docente se coloca perante ambos os processos, bem como a própria relação que acaba por se estabelecer entre os diferentes atores. Álvarez Méndez, citado por Vieira e Moreira (2011: 22) recorda que o facto de se associarem finalidades tão distintas num mesmo modelo de ADD conduz, muitas vezes, o processo de avaliação de forma "desalinhada dos fins educativos e formativos que deveria perseguir", acabando por permanecer "longe da actividade de construção de conhecimento que deveria constituir".

Atrever-nos-íamos, ainda, a colocar a seguinte questão: no âmbito da $\mathrm{ADD}$, a supervisão, porque exercida entre pares, não revestirá, à partida, um caráter problemático? E nesse caso, não será legítimo presumir que se desvirtua o processo supervisivo, enquanto prática reflexiva de formação contínua de professores, e como metodologia, instrumento e estratégia de regulação, apoio, cooperação/colaboração, autoaprendizagem, partilha de conhecimento? Não pretendendo dar uma resposta imediata à pergunta formulada apraz-nos, contudo, destacar as palavras de Vieira e Moreira (2011: 9) quando sublinham que "o potencial da avaliação e da supervisão joga-se no campo das possibilidades, entre o que são e o que deveriam ser, 
insurgindo-se contra o sistema mas operando no seu seio e segundo as suas regras". Assim, no pior dos casos, representarão um processo essencialmente burocrático e formal que servirá os professores ainda que lhes seja vedado, porém, o acesso à contestação. $\mathrm{Na}$ melhor das possibilidades, serão apropriadas pelos professores como estratégias para a autocrítica, a desocultação de constrangimentos e a "reconstrução individual e colectiva da profissionalidade docente, ao serviço de uma educação transformadora e emancipatória" (idem). As mesmas autoras confirmam, no entanto, que, na sua opinião, a grande maioria das situações deverá situar-se entre os dois extremos sugeridos.

Partindo dos pressupostos descritos, podemos concluir que a avaliação e a supervisão deverão procurar desbravar os tortuosos caminhos que as sujeitam a uma lógica de controlo e sujeição para construir vias assentes numa lógica de transformação e emancipação reconhecendo, à partida, que as duas lógicas coexistem em conflito e geram dilemas com os quais é preciso aprender a lidar.

\section{O PAPEL DO SUPERVISOR / AVALIADOR}

No âmbito do novo modelo de ADD, legislado pelo Decreto-Lei n. ${ }^{\circ}$ 41/2012, de 21 de fevereiro, o supervisor pedagógico / avaliador continuará a ser escolhido de entre os seus pares, através de uma avaliação interna e/ou externa. $\mathrm{Na}$ primeira, será selecionado "segundo o princípio da hierarquização". Já a avaliação externa "centra-se na dimensão científica e pedagógica e realiza-se através da observação de aulas por avaliadores externos" (artigo $42^{\circ}$ ), ainda que "da mesma área científica do avaliado, detentores de formação prioritariamente especializada na área da avaliação do desempenho docente ou com experiência em supervisão pedagógica" (Preâmbulo).

Sendo-lhe conferido legalmente o poder supervisivo / avaliativo, competirá ao seu titular, e desde o primeiro instante, a implementação de dois princípios éticos fundamentais da sua atuação: o da transparência e o da confiança mútua, constituintes basilares para a consideração da supervisão como uma negociação. De outro modo, os riscos de relações problemáticas serão ampliados, com antagonismos e litígios entre avaliadores e avaliados, que influenciarão, inevitavelmente, o clima da escola. Este é o cenário que as competências, a perspicácia e sensibilidade do supervisor, par entre pares, terá que evitar, adotando a postura e modelo de supervisão adequados ao contexto das competências e performances que lhe caberá avaliar. Na verdade, e tal como Vieira e Moreira (2011: 23) recordam, mesmo quando parece existir um perfeito consenso entre as partes, "a acção do supervisor / avaliador será sempre fortemente potenciadora de estratégias de resistência por parte do professor avaliado / supervisionado".

Para além dos princípios referidos, e partindo do pressuposto que o mentor ou supervisor desempenha um papel modelo, há também que 
valorizar a sua credibilidade como profissional. Competir-lhe-á, então e entre outras, a exigente função de favorecer a otimização das capacidades pessoais e profissionais dos avaliados, através da monitorização, observação e avaliação sendo que o seu papel deverá ser balizado à luz de uma dimensão positiva, com um leque de funções facilitadoras e encorajadoras nas quais se enquadram as funções de informar, sugerir, criticar e encorajar. Outros prérequisitos que, na opinião de Reis (2011: 17) são essenciais incluem as capacidades de "ouvir, apoiar, reflectir, analisar, discutir, organizar, definir objectivos e metas, ser flexível e acessível". A estes acrescem outras competências que se prendem com as relações interpessoais e de comunicação que, na esteira do mesmo autor, "são decisivas no estabelecimento de uma relação de supervisão centrada na colaboração, no apoio e no aconselhamento tendo em vista o desenvolvimento de práticas lectivas adequadas" (idem). Na realidade não é por acaso que os modelos de ADD no nosso país têm sofrido sucessivas alterações, nomeadamente no que ao papel do avaliador diz respeito. Efetivamente, e no âmbito da sua implementação, é permanente a discussão que apela às competências dos supervisores / avaliadores e que se prendem, por um lado, ao seu caráter (ponderação, serenidade, bom senso, paciência) e, por outro, ao seu perfil ético (idoneidade, profissionalismo, sentido do dever, isenção) tal como já foi, anteriormente, mencionado. Certo é que nenhum modelo de supervisão pode resultar, nem nenhum perfil de supervisor pode prevalecer se os princípios da confiança mútua e transparência forem esquecidos ou traídos, o que subverterá, entre outros aspetos, o envolvimento positivo dos sujeitos envolvidos (observadores / avaliadores e/ou observados / avaliados) na problematização e valorização da sua profissão e a qualidade e eficácia dos resultados esperados.

Glickman (cit. por Vieira \& Moreira, 2011, pp. 15-16), reportando-se às funções do supervisor, problematiza o que designa como "estilos supervisivos" e caracteriza 3 estilos principais: o não-diretivo; o colaborativo e o diretivo (que se subdivide ainda em diretivo informativo e diretivo de controlo). Na opinião das autoras a necessidade de um estilo diretivo prendese com a capacidade de tomada de decisões: quanto menor for a do professor em tomar decisões mais se justificará um estilo diretivo. No caso da ADD parece justificar-se o recurso ao estilo não-diretivo da supervisão na medida em que é este o estilo onde predominam as funções de "prestar atenção, clarificar, encorajar e servir de espelho".

Outra das funções principais do supervisor / avaliador prende-se, justamente, com a documentação do desempenho docente. Este, na opinião de investigadores como Stronge (2010: 39-40), deverá ser documentado, não a partir de uma, mas de múltiplas fontes de dados já que, deste modo, o avaliador terá a oportunidade de identificar e compreender as opções curriculares e letivas adotadas pelo professor e, simultaneamente, aferir o grau de cumprimento das mesmas, tendo por referência o definido como desejável. Por outro lado, o recurso a múltiplas fontes num sistema de 
avaliação de professores tende a configurar uma imagem do desempenho profissional próxima do real, facto que proporciona uma sólida plataforma para a construção de planos de melhoria realistas e adequados às necessidades específicas de cada professor. Este pressuposto contribuirá, certamente, para "garantir uma medição mais precisa" (Stronge, 2010: 35) e proporcionar uma "visão mais completa e mais justa do desempenho" (ibidem). De entre as fontes de dados mais utilizadas destaca-se, segundo o mesmo autor, a observação, os inquéritos a alunos, o portefólio do professor, os dados de desempenho dos alunos e a autoavaliação. Salientamos a observação que, na perspetiva deste investigador, inclui a observação formal de aulas / trabalho, a observação contínua do desempenho e a do trabalho do aluno sendo que, no que toca à primeira, ainda que útil para a melhoria, é limitativa se utilizada como único processo de recolha de dados porquanto pode conduzir a realidade de uma aula observada a uma situação artificial e falaciosa.

Também com o intuito de concretizar e operacionalizar os princípios de supervisão que remetem, na perspetiva de Vieira e Moreira (2011: 27) para a "indagação crítica, intervenção crítica, democraticidade, dialogicidade, participação e emancipação" recordamos as estratégias supervisivas que estas autoras destacam: Auto-questionamento / Auto-avaliação; Diálogo Reflexivo; Análise documental; Inquérito; Observação de aulas; Narrativas profissionais; Portefólio de ensino; Investigação-ação. Todas as estratégias comportam formas de registo / recolha de informação específicos sendo que a dimensão estratégica a adotar deverá pressupor uma "intencionalidade e um esquema de acção, o qual poderá ter diferentes graus de extensão temporal, amplitude ou sistematicidade" (idem). De entre as estratégias mencionadas salientaremos, doravante, a observação de aulas pela razão principal que é a que se enquadra no modelo de ADD que se tem implementado no nosso país. Como Vieira e Moreira sublinham (2011: 28), trata-se de uma estratégia privilegiada de "recolha de informação incidente na dimensão identitária da acção docente: a dimensão da pedagogia".

\section{A OBSERVAÇÃO DE AULAS: UM CASO REAL}

Alarcão e Tavares (2003: 120) recordam o modelo de supervisão clínica sublinhando que na sua conceção original trata-se de um modelo que constitui um "processo de envolver os professores na análise da sua praxis de modo a que os problemas que vão surgindo dêem origem a hipóteses e soluções que, experimentadas pelo próprio professor, possam contribuir para uma prática de ensino mais eficaz, mas também mais comprometida, mais pessoal e mais autêntica". Os mesmos autores sublinham que este tipo de supervisão atua de dentro para fora da sala de aula, de onde se destacam a observação e reflexão do próprio ensino e a colaboração e entreajuda dos colegas. Na realidade, trata-se duma relação de colaboração entre colegas que 
na "clínica" da sala de aula tomam o processo de ensino/aprendizagem como objeto de reflexão e fonte de hipóteses de solução e mudança. Segundo Moreira (2001: 88), a supervisão clínica implica uma relação entre supervisor e professor assente em princípios como a confiança mútua, a liberdade de expressão, a autonomia e a colegialidade, sendo a sala de aula o objeto da ação supervisiva e a fonte de informação primária para o processo de análise do ensino do professor e tomada de decisões educativas. Refere-se, portanto a uma relação franca entre o supervisor e o professor, centrada no desempenho que o último desenvolve na sala de aula, objetivando a melhoria da prática de ensino.

Vieira e Moreira (2011: 29), citando Goldhammer et al. (1980: 26-27) acrescentam algumas características deste modelo de supervisão nas quais se enquadram a orientação por finalidades, combinando "necessidades individuais e colectivas de desenvolvimento profissional"; o facto de se tratar de um modelo sistemático, "embora requeira uma flexibilização e actualização constante da sua metodologia"; a pressuposição de que o supervisor deverá, a priori, deter um maior conhecimento acerca da instrução e da aprendizagem e possua, simultaneamente, formação específica, entre outras.

O modelo centra-se, como já vimos, na observação e análise colaborativa das práticas de ensino e aprendizagem com o objetivo de as melhorar e é operacionalizado através daquilo que muitos investigadores (Vieira e Moreira, 2011: 29 e Reis, 2011: 20) designam de "ciclos de observação" ocorrendo em três fases principais: Pré-observação / Antes da observação; Observação / Durante a observação e Pós-observação / Após a observação. Partindo dos pressupostos até agora enunciados e procurando circunscrever este trabalho à estratégia supervisiva - observação de aulas - procuraremos dar-lhe corpo através de uma breve análise da sua aplicação numa determinada escola, com base na revisão de alguma da literatura existente.

A observância e concretização destes ciclos de observação são fulcrais porquanto estão em causa a melhoria da qualidade das práticas, a par com um momento de avaliação formal. Na realidade, e tal como preconizam Vieira e Moreira (2011: 31), "Observar uma aula sem que haja um encontro prévio e outro posterior corresponde a anular a dimensão dialógica da observação e a co-responsabilização dos actores nas tarefas que a observação formativa implica. Ao fazê-lo, estamos também a reduzir a sua fiabilidade, na medida em que apenas o juízo do observador é colocado em jogo". É impossível, naturalmente, discordar-se da opinião destas investigadoras embora saibamos que, na grande maioria dos casos, as escolas e os professores não dispõem de condições (tempo, recursos humanos, condições físicas e materiais...) que possibilitem a concretização do ciclo na sua totalidade. Porém, devem ser encontradas alternativas através do correio eletrónico ou até de registos reflexivos trocados entre os docentes de modo a que não se despreze e se 
perca o potencial formativo da observação. No caso que apresentamos ${ }^{\dagger} \mathrm{o}$ ciclo não foi, na realidade, concretizado e a principal razão prendeu-se com o facto de não ter sido encarado o caráter formativo nem da observação da aula nem tampouco da avaliação do desempenho. Efetivamente, ao invés do encontro de pré-observação no qual se deve levar a cabo uma discussão / negociação sobre os objetivos da aula, das estratégias definidas para a sua concretização e onde se assumem as intenções do docente observado e não do observador (Reis, 2011: 21), os encontros fugazes que realmente tiveram lugar serviram tão-somente para proceder à entrega das planificações das aulas a serem observadas e dos respetivos materiais. Não existiu, portanto, qualquer guião de pré-observação como alguns investigadores propõem (Vieira e Moreira, 2011: 32 e Reis, 2011: 23), nem quaisquer questões acerca das aulas em causa e o único momento de negociação existente prendeu-se com a calendarização das mesmas.

Para as aulas observadas foi utilizada uma grelha de observação. Na opinião de Vieira e Moreira, (2011: 33) as grelhas de observação "podem objectivar o enfoque e criar uma base de reflexão para os professores, para além de instigarem a explicitação das suas teorias pessoais acerca do ensino e da aprendizagem" pressupondo-se, simultaneamente, que a grelha incorpore uma visão de educação devendo ser discutida e/ou construída com o professor que vai ser observado. A este respeito a escola em geral e os supervisores / avaliadores em particular, agiram em conformidade. Com efeito, os professores foram implicados na conceção local do sistema de avaliação na medida em que, em reuniões de grupo disciplinar, debateram as fichas de avaliação e de observação, teceram comentários e elaboraram sugestões e propostas de alteração. Ao analisarmos a grelha de observação utilizada percebemos, logo à partida, que a mesma não passou de uma lista de verificação, cujos indicadores a observar refletiam, claramente, uma colagem aos parâmetros de avaliação do desempenho docente transformando-a, de forma inequívoca, num instrumento detalhado de avaliação sumativa e com um valor formativo obviamente questionável. Mais ainda: esta quase que "clonagem" de parâmetros impossibilitou que um grande número de indicadores fosse observado o que resultou, neste caso concreto, em inúmeras avaliações finais de aulas observadas classificadas como "Excelentes". Com efeito, em praticamente todas as grelhas de observação foram muitos os campos assinalados com o item "Não observado" sendo que, para se proceder ao cálculo final da avaliação qualitativa, se multiplicava o número de respostas com o valor "Sim" apenas pelos indicadores observados. Por outro lado, os aspetos a avaliar indicados na grelha estavam, na nossa opinião, claros e objetivos.

\footnotetext{
${ }^{\dagger}$ Processo que decorreu numa escola não agrupada, no ciclo avaliativo 2009/2011, de acordo com a legislação em vigor na altura (Decreto regulamentar n. ${ }^{\circ}$ 2/2010, de 23 de junho).
} 
Uma outra crítica a registar tem a ver com o facto de a avaliação a efetuar pelo observador e pelo observado se encontrar na mesma grelha de registo. Não se possibilitou que se enquadrassem dois dos procedimentos gerais de utilização de grelhas de observação preconizados por Vieira e Moreira (2011: 34) e que nos parecem fundamentais: reunião entre os professores observador e observado com o intuito de discutir a aula observada à luz das dimensões da grelha através do confronto de registos e perspetivas; relatório sumário do ciclo de observação pelo professor observador e, eventualmente, pelo professor observado através da partilha de relatórios. Na verdade, o único "relatório" efetuado pelo observador foi o preenchimento da grelha de observação e ao observado coube a possibilidade de redigir um relatório de autoavaliação onde, entre outros elementos da sua avaliação de desempenho, enquadrou as observações de aulas.

A última fase do ciclo - a Pós-observação -não foi, portanto, concretizada. Nas palavras de Pedro Reis (2011: 53), a análise, discussão e reflexão feitas após a observação "constituem o cerne de qualquer processo de desenvolvimento profissional de professores, permitindo desafiar o status $q u o$, estimular a criatividade na superação de dificuldades e problemas detetados, e desenvolver diferentes dimensões do conhecimento profissional" e o facto de esta última fase não ter sido levada em linha de conta constitui um enorme constrangimento e condiciona claramente a função formativa desta estratégia supervisiva.

Podemos concluir, depois destas constatações, que neste ciclo de observação / avaliação falhou aquilo que Stronge (2010: 32) designa de "comunicação privada". Efetivamente e tal como referido, verificaram-se alguns "encontros" mas apenas para proceder à entrega de materiais e planificações e para proceder à calendarização das aulas a observar e para, depois de concluído o processo de avaliação entre avaliador e avaliado, solicitar um parecer acerca da avaliação que, na realidade, apenas se tratou de "confirmar" a avaliação já efetivada pelo observador / avaliador. A comunicação bilateral contínua, o acompanhamento e a monitorização do docente observado / avaliado ao longo do período de observação / avaliação, efetivamente, não existiram. $\mathrm{O}$ docente foi avaliado somente no final do período a que se reporta a avaliação não tendo sido acompanhado, através de feedback contínuo sobre o desempenho com vista ao seu aperfeiçoamento e à melhoria das práticas educativas. Na verdade, os relatores designados apenas "representaram" o seu papel por se encontrarem num escalão igual ou superior ao dos seus avaliados sendo de reconhecer, contudo, que não havia no agrupamento conhecimento de docentes especialistas na área. Não obstante, também não foram disponibilizados quaisquer outros docentes especialistas para prestar o apoio necessário $\mathrm{e}$, por conseguinte, não foram orientados os professores com maiores dificuldades no seu trabalho. Note-se que das estratégias supervisivas mencionadas anteriormente apenas a observação de aulas foi implementada o que reflete, claramente, o modo como se processou o ciclo. 


\section{BREVE CONCLUSÃO}

Perante o exposto no caso real que descrevemos, consideramos que todos os princípios que subjazem a um processo de ADD, bem como os que respeitam a uma supervisão de qualidade foram, na nossa humilde opinião e aludindo a este caso, desvirtuados e subvertidos. Mais ainda: não foi possível identificarmos e combinarmos uma lógica formativa, com vista ao desenvolvimento profissional, com uma lógica sumativa, de prestação de contas, com o objetivo de incrementar o sucesso escolar dos alunos.

Assumimos, contudo, o compromisso de, futuramente, reivindicarmos um processo de supervisão / avaliação com significado e sentido, que aposte claramente na dimensão interna, formativa, colaborativa. Estamos conscientes de que é fulcral que apostemos na construção de uma cultura profissional que se resgate da clausura, da solidão e do sofrimento profissional e que avance ao encontro do equilíbrio, da harmonia, do poder construtivo. Sabemos que tal pressuposto é tangível mas compete a todos pelo que é crucial que cada um cumpra com a sua parte e dê o seu contributo.

\section{ALGUMAS CONSIDERAÇÕES FINAIS}

A sociedade atual em que vivemos caracteriza-se pela mudança sistemática, pela pressão do tempo, pelo acesso rápido à informação e pelo significativo avanço tecnológico acabando por, direta ou indiretamente, suscitar nos cidadãos, em geral, e nos professores, em particular, a necessidade de produzir uma resposta imediata e capaz de responder às novas tendências, necessidades e interesses. Afinal, está nas suas mãos a formação das futuras gerações.

É precisamente na sequência da procura de novas formas de desenvolvimento da profissionalidade docente que Moreira (2004: 134) considera que "a supervisão pedagógica institui-se como instrumento de transformação de sujeitos e das suas práticas nos contextos (i)mediatos da acção pedagógica". Assim, é nosso dever aspirar mas também lutar, como é preconizado por Moreira (2009: 253), pela prevalência de tendências supervisivas assentes numa "concepção democrática da supervisão", onde se procure privilegiar o espaço de reflexão e aprendizagem colaborativa e horizontal e, simultaneamente, o desenvolvimento e implementação de mecanismos potenciadores da autosupervisão e da autoaprendizagem, bem como a capacidade de gerar e partilhar o conhecimento, ascendendo a um cada vez mais significativo desenvolvimento da autonomia profissional.

$\mathrm{Na}$ realidade, e a partir do momento em que é colocado em prática um contexto avaliativo de supervisão interpares, impõe-se uma postura crítica, interventiva e ativa por parte dos professores, no sentido de trabalhar para a melhoria da qualidade das suas práticas e, consequentemente, para a promoção da melhoria da aprendizagem dos alunos. Assim, deve-se insistir 
na dinamização da reflexão partilhada, na reivindicação de tempo para experimentar e para testar, na partilha de materiais, de metodologias e procedimentos, no apoio e confiança mútuos, no recurso à observação de aulas encarando-as numa perspetiva colaborativa e, sobretudo na predisposição para uma aprendizagem e melhoria contínuas que deverá ocorrer num ambiente de confiança e de democratização.

Quanto à questão da avaliação de professores e tratando-se de um processo cuja finalidade consiste em determinar o desempenho dos docentes no contexto de um vasto conjunto de circunstâncias, a necessidade de uma ação supervisiva contínua e reflexiva, de forma a assegurar a melhoria individual, institucional e da qualidade do sistema educativo afigura-se como fulcral. Assim, uma avaliação de desempenho de qualidade constitui-se, inequivocamente, como um dispositivo reprodutor da promoção da aprendizagem ao longo da vida e, por conseguinte, da eficácia pedagógica das práticas docentes.

Dada a complexidade da atividade docente, são inúmeros os fatores que podem afastar a avaliação do desempenho docente do quadro de uma escola reflexiva. Com efeito, a perspetiva formativa da avaliação de desempenho pode, eventualmente, ser "travada pela sua dimensão sumativa", como referem Machado e Formosinho (2010: 108), se acentuado o caráter seletivo, de controlo e inspeção da mesma, com especial enfoque na eficiência e produtividade. Este aspeto pode, ainda, reduzir a supervisão a um mero dispositivo de "certificação e legitimação, de domínio e controlo do sistema e das carreiras" (idem: 109), por oposição ao perfil formativo conducente ao aperfeiçoamento e melhoria pretendidos uma vez que é percecionada como uma ação de verificação e controlo da ação docente, que é exercida por um avaliador sobre um avaliado.

É fundamental recordarmos que qualquer mudança em educação deve ter como objetivo primordial a melhoria da ação educativa da escola, cujo resultado direto seja a melhoria das aprendizagens e do bem-estar dos alunos. Em nosso entender, essa melhoria passa, sem dúvida, pela formação dos professores, quer contínua, de caráter mais generalista, quer a formação especializada que qualifique os professores para a multiplicidade e complexidade crescentes de funções que lhe vêm sendo acometidas de forma exponencial nos últimos anos. A avaliação docente deve constituir-se, igualmente, como um dos instrumentos ao serviço desse mesmo desígnio. Para tanto, e porque os professores são os agentes centrais das mudanças nas escolas e a sua ação o elemento fulcral para a prossecução do objetivo da melhoria, essa avaliação deve criar condições que impulsionem o professor para uma atitude reflexiva sobre a sua atividade letiva, facilitando a deteção e $\mathrm{o}$ reconhecimento de fragilidades e contribuindo para o desenvolvimento e aperfeiçoamento da sua ação educativa.

Ainda no atinente à avaliação de desempenho docente, a par do consenso retórico quanto à sua necessidade, temos assistido a tentativas frustradas da sua implementação que se transformam num desperdício de meios e energias. 
Em primeiro lugar, parece-nos que um modelo de avaliação que não resulte de um processo de reflexão conjunta e negociação de que os visados tomem parte, será sempre percecionado como uma imposição top-down e a jusante e, por isso, rececionada com desconfiança e alvo de rejeição. Em segundo lugar, os professores estão socializados com uma progressão linear, pelo que tendem a rejeitar qualquer avaliação que tenha tradução na verticalidade da carreira.

Terminamos esta breve reflexão aludindo ao que tem sido apontado como uma excelente medida potenciadora do trabalho colaborativo e da função formativa da avaliação docente: a concessão de tempo livre aos professores para observação de professores experientes. Com efeito, esta medida traduz uma situação que, pelo menos para já, não está prevista no nosso país e na nossa legislação. $\mathrm{Na}$ verdade, muito dificilmente um diretor poderia "dispensar" tempo livre a docentes para poderem concretizá-lo a avaliar pela organização e distribuição do serviço docente e da carga horária a que é obrigado dar cumprimento. Por outro lado, cremos que as escolas no nosso país ainda se encontram muito fechadas ao diálogo e ao reconhecimento de que a mudança e a melhoria são vitais, razão pela qual ignoram que haja, efetivamente, docentes mais competentes e experientes, capazes de contribuir largamente para a melhoria das práticas pedagógicas de todos. $\mathrm{O}$ professor em Portugal continua a manifestar, de um modo geral, muita mesquinhez em aceitar que pode, realmente, aprender com os seus pares e que o trabalho colaborativo / interpares é fulcral para a melhoria e para a qualidade do desempenho profissional. Parece-nos fundamental que, num futuro próximo, se deva incutir, nas organizações educativas, o espírito de trabalho colaborativo e de cultura de partilha no sentido de promover grupos de trabalho e de discussão, mesas redondas de modo a instalar o "clima construtivo" defendido por Stronge (2010: 31) integrando, se possível, especialistas na área da avaliação. E tentar fazê-lo, o mais possível, de forma voluntária. Só assim conseguiremos desmistificar muitas das crenças e receios dos professores. Enquanto tal não se verificar, julgamos que será muito difícil assumirmos um verdadeiro compromisso organizacional para com a observação / avaliação.

\section{REFERÊNCIAS BIBLIOGRÁFICAS}

Alarcão, I. e Roldão, M. (2010). Supervisão - Um contexto de desenvolvimento profissional dos professores. $2^{\mathrm{a}}$ edição. Mangualde: Edições Pedago.

Alarcão, I. e Tavares, J. (2003). Supervisão da prática pedagógica - Uma perspectiva de desenvolvimento e aprendizagem. Coimbra: Livraria Almedina.

Formosinho, J., Machado, J e Oliveira-Formosinho, J. (2010). Formação, Desempenho e Avaliação de Professores. Mangualde: Edições Pedago. 
Lamy, F (2009). Supervisão pedagógica. Vila Nova de Gaia: Edições Asa. Revista Correio da Educação, n. ${ }^{\circ}$ 339. Consultado em http://www.asa.pt/CE/PDF/339/CE_339_Artigo_2.pdf.

Machado e Formosinho. (2010). Desempenho, mérito e desenvolvimento Para uma avaliação mais profissional dos professores. In Formação, Desempenho e Avaliação de Professores. Pp. 97-118. Mangualde: Edições Pedago.

Moreira, M. (2001). A investigação-ação na formação reflexiva do professor estagiário de Inglês. Lisboa: Instituto de Inovação Educacional.

Moreira, M. (2004). O papel da supervisão numa pedagogia para a autonomia. In F. Vieira et al. (orgs.), Pedagogia para a Autonomia: Reflectir e Agir Estrategicamente. Actas do $2^{\circ}$ Encontro do Grupo de Trabalho - Pedagogia para a Autonomia. Pp. 133-147. Braga: CIEd. Consultado em http://repositorium.sdum.uminho.pt/handle/1822/4115

Moreira, M. (2009) A avaliação do (des)empenho docente : perspectivas da supervisão pedagógica. In Vieira, F. et al. (orgs). - Pedagogia para a autonomia : reconstruir a esperança na educação: actas do Encontro do Grupo de Trabalho-Pedagogia para a Autonomia, 4, Braga, 2009. Braga: CIED. pp. 241-258. Consultado em http://repositorium.sdum.uminho.pt/handle/1822/10366.

Reis, P. (2011). Observação de aulas e avaliação do desempenho docente. Conselho Científico para a Avaliação de Professores. Consultado em http://www.ccap.min-edu.pt/docs/Caderno_CCAP_2-Observacao.pdf.

Stronge, J. (2010). O que funciona, de facto, na avaliação de professores: breves considerações. In Flores, M. (org.) A avaliação de professores numa perspectiva internacional. Sentidos e implicações. (pp. 23-43) Porto: Areal Editores.

Vieira, F. e Moreira, M. (2011). Supervisão e avaliação do desempenho docente. Para uma abordagem de orientação transformadora. Conselho Científico para a Avaliação de Professores. Consultado em http://www.ccap.min-edu.pt/docs/Caderno_CCAP_1-Supervisao.pdf.

\section{LEGISLAÇÃO CONSULTADA}

Despacho n. ${ }^{\circ} 16$ 034/2010, de 22 de outubro

Decreto-Lei n. ${ }^{\circ} 41 / 2012$, de 21 de fevereiro

Despacho n. ${ }^{\circ} 5464 / 2011$, de 30 de março

Decreto Regulamentar n. ${ }^{\circ}$ 26/2012, de 21 de fevereiro.

The greatest danger for most of us is not that our aim is too high and we miss it, but that it is too low, and we realize it.

Michelangelo

\footnotetext{
${ }^{\star}$ http://www.leadershipnow.com/visionquotes.html
} 